\title{
ELEMENTOS CONSTITUINTES E CONSTITUIDORES DA FORMAÇÃO CONTINUADA DE PROFESSORES: CONTRIBUIÇÕES DA TEORIA DA ATIVIDADE ${ }^{1}$
}

\author{
Patricia Lopes Jorge Franco* \\ Andréa Maturano Longarezi**
}

\section{RESUMO}

O artigo sistematiza os pressupostos teórico-metodológicos da Teoria da Atividade de Leontiev (1983), destacando os elementos constituintes e constituidores da formação continuada de professores. Inicialmente apresenta-se uma síntese dos fundamentos antropológicos e filosóficos que delineiam o olhar leontieviano, considerando categorias trabalho; consciência; objetivação e alienação, bem como o desenvolvimento humano em toda sua complexidade. Discute os elementos constitutivos da Teoria da Atividade: atividade dominante, estrutura da atividade, significação social e sentido pessoal. Com base nesse corpus teórico, analisa a formação docente como atividade, na qual se entende que pela atividade dominante o professor se desenvolve. A atividade é ponto de partida e chegada do processo formativo profissional, pois possibilita aproximação direta do conteúdo da ação formativa com suas necessidades. Conclui-se, portanto, que os elementos constituintes e constituidores da formação continuada, na perspectiva apontada, são potencializadores do desenvolvimento humano-

\footnotetext{
* Mestre em Educação pela Universidade de Uberaba (UNIUBE). Coordenadora de ações formativas no Centro Municipal de Assistência Pedagógica e Aperfeiçoamento de Professores de Ituiutaba/MG - CEMAP. Professora orientadora do Mestrado em Educação e Psicanálise - INSET/Polo de Ituiutaba/MG.

E-mail: pjfranco@netsite.com.br

** Doutora em Educação Escolar pela UNESP/ Araraquara. Professora Adjunta da Universidade Federal de Uberlândia. Membro do Programa de Pós-Graduação em Educação (Mestrado e Doutorado) da Faculdade de Educação (UFU).

E-mail: andrea@faced.ufu.br

${ }^{1}$ Apoio Financeiro do CNPQ e da FAPEMIG.
} 
social e contribuem para superação de rupturas entre sentido e significado desta formação.

Palavras-chave: Formação continuada de professores. Teoria da Atividade. Significação social. Sentido pessoal. Atividade dominante.

\begin{abstract}
This article systematizes the theoretical methodological assumptions of Activity TheoryLeontiev(1983), focusing on the constitutiveand constitutors elements of the teacher's continuous formation. Firstly, it presents a synthesis of anthropological and philosophical foundations that lines the leontievian view, considering categories work; conscience; objectiveness; and alienation as well as the human development in its complexity. It discusses the constitutive elements of Activity Theory: dominant activity, structure of activity, social meaning and personal meaning. Based on this theoretical corpus, it analyzes the teacher's formation as activity, taken as the dominant activity in what the teacher develops his/herself. The activity is the initial and final point of the professional formative process since it makes possible the direct approach of formative action content and their needs. It is concluded that the constitutive and constitutors elements of continued formation, in this perspective, are enablers of human-social development and contribute to the overcoming of the ruptures between the sense and meaning of this formation.
\end{abstract}

Keywords: Continued teacher's formation. Activity Theory. Social meaning. Personal sense. Dominant activity.

O desenvolvimento histórico-social dos homens e o desenvolvimento individual do gênero humano se processam mediante a atividade prática sensorial. Essa é a premissa do materialismo históricodialético com a qual os psicólogos soviéticos Vigotski, Luria, Leontiev, entre outros buscam defender, e elegem o conceito de atividade como um dos princípios centrais do desenvolvimento do psiquismo. 
Essa corrente teórica compreende que a atividade socialmente significativa é o princípio explicativo da consciência, ou seja, a consciência é construída de fora para dentro por meio das relações sociais (KOZULIN, 2002). Assim, consciência e atividade são entendidas como unidades dialéticas, elementos fundamentais à psicologia histórico-cultural.

A gênese da atividade docente é melhor compreendida quando apreendida em sua estrutura social, no modo em que opera suas relações. Nesse contexto é que a docência, enquanto função social vai se constituindo como tal: "[...] como produto ou funções de relações sociais concretas, objetivas, dentro de uma estrutura social que determina o seu comportamento como indivíduo" (VAZQUEZ, 1977, p. 427).

As relações que ocorrem dentro dessa estrutura social e econômica estão balizadas num modo de produção capitalista. Marx (1989) estuda a essência das relações capital-trabalho e analisa o trabalho como elemento determinante da natureza humana. Seu objetivo é o de descortinar a formação social, o trabalho humano, as relações sociais e os homens, constituintes e constituidores desse modo de organização social, econômica, política, enfim, de sua consciência individual. Portanto, discutir os processos formativos dos professores implica analisar os processos contraditórios presentes na estrutura social econômica e nas relações sociais, enfim, analisar a natureza do trabalho, a docência e, consequentemente, em que condições e como se efetiva a formação continuada docente.

O homem não nasce dotado das aquisições históricas da humanidade. [...] Só apropriando-se delas no decurso da sua vida ele adquire propriedades e faculdades verdadeiramente humanas. Este processo coloca-o, por assim dizer, aos ombros das gerações anteriores e eleva-o muito acima do mundo animal (LEONTIEV, 1978, p. 282-283).

A apropriação é um processo essencial que ocorre no desenvolvimento do ser humano, ao longo de sua história social, mediatizada pelas relações com o mundo circundante e com os homens. O ser humano não se adapta ao mundo dos objetos e fenômenos humanos, como acontece com os animais, pelo contrário, o homem os faz serem seus, por meio de sua ação, de sua atividade produtiva, daquilo que para ele 
tem significado. Por isso, diz-se que é um processo ativo e não adaptativo como o dos animais.

Os objetos apropriados e produzidos pelos homens, através das relações estabelecidas entre si por meio da linguagem, são decorrentes da atividade humana e adquirem uma existência objetiva. Esse processo, na perspectiva histórico-cultural é definido como objetivação:

A atividade física ou mental dos seres humanos transfere-se para os produtos dessa atividade. Aquilo que antes eram faculdades dos seres humanos se torna, depois do processo de objetivação, características por assim dizer "corporificadas" no produto dessa atividade, o qual, por sua vez, passa a ter uma função específica no interior da prática social (DUARTE, 2005, p. 33).

Tudo quanto o homem produz e reproduz na sociedade tem relação intrínseca com a sua prática social, com o significado socialmente dado ao que foi produzido, ou seja, à sua função social. "O processo de objetivação da cultura humana não existe sem o seu oposto e ao mesmo tempo complemento, que é o processo de apropriação dessa cultura pelos indivíduos" (DUARTE, 2005, p. 34). Daí que para considerar o processo de apropriação da cultura formativa dos professores é imprescindível analisar sua atividade social, isto é, sua docência, suas necessidades pessoais, profissionais e demais relações sociais no interior desta atividade. Isto requer compreender tais necessidades em sua construção histórica.

Não se pode separar o que constitui a natureza humana, [...] "a atividade humana se objetiva em produtos culturais, sejam eles materiais ou não, temos, como conseqüência, que o processo de objetivação do gênero humano é cumulativo" (DUARTE, 2005. p. 34). Assim percebe-se que a sua atividade docente vai constituindo-se, transformando-se ao longo de sua trajetória. Então, não há como dissociar o professor de sua ação/formação.

Portanto, é salutar considerar o contexto da prática social do professor e como este estabelece entre seus pares e a realidade social uma prática formativa, o que pensam de sua própria formação docente e como vislumbram novas formas de aprimoramento pessoal e profissional no decorrer de sua atividade. 
O exercício da docência, como também a maioria das atividades humanas, desde seu início, ocorre de forma coletiva. Por conseguinte, acredita-se que analisar como essas relações sociais são estabelecidas entre si é fundamental, pois são formas de apropriações de experiências sociais, num processo educativo continuado. Esse processo pode ocorrer consciente e outras vezes inconscientemente, direta ou indiretamente, intencional ou não intencionalmente.

Compreender a realidade concreta dos indivíduos, desvelando elementos não aparentes; apreender as contradições existentes no próprio movimento da história, na constituição da cultura formativa docente; é um esforço que se faz necessário se considerado uma abordagem crítico-diálética.

Nesta perspectiva, Kosik (1995) incorpora duas relações fundamentais do marxismo: a relação do homem com a natureza que se efetiva pelo trabalho e a dimensão da luta de classes. Para Kosik (1995), analisar o mundo da pseudoconcreticidade ${ }^{2}$, a falsa ideia do real, a aparência enganadora de que o mundo fetichizado ${ }^{3}$ esconde do homem e como lutar pela sua destruição, é buscar compreender a realidade concreta. Esta ocorre no mundo da práxis, que, segundo Kosik (1995), é entendida com as seguintes definições:

[...] a práxis utilitária cotidiana cria o pensamento comum - em que são captados tanto a familiaridade com as coisas e o aspecto superficial das coisas quanto a técnica de tratamento das coisas como forma de seu movimento e de sua existência. O pensamento comum é a forma ideológica do agir humano de todos os dias.; a práxis fetichizada, o mundo que se manifesta ao homem, não é o mundo real, embora tenha a consistência e a validez do mundo real: é o mundo da aparência. A representação da coisa não constitui uma qualidade natural da coisa e

\footnotetext{
${ }^{2} \mathrm{O}$ mundo da pseudoconcreticidade é um claro-escuro de verdade e engano. $\mathrm{O}$ seu elemento próprio é o duplo sentido. $\mathrm{O}$ fenômeno indica a essência e, ao mesmo tempo, a esconde. A essência se manifesta no fenômeno, mas só de modo inadequado, parcial, ou apenas sob certos ângulos e aspectos (KOSIK, 1995, p. 11).

${ }^{3} \mathrm{O}$ mundo fetichizado é o mundo do tráfico e da manipulação, das representações comuns, que são projeções dos fenômenos externos na consciência dos homens (a qual não coincide com a práxis crítica revolucionária da humanidade) (KOSIK, ibidem).
} 
da realidade: é a projeção, na consciência do sujeito, de determinadas condições históricas petrificadas.; a práxis revolucionária consiste saber que a realidade pode ser mudada de modo revolucionário só porque e só na medida em que nós mesmos produzimos a realidade, e na medida em que saibamos que a realidade é produzida por nós. O homem pode mudar e transformar de modo revolucionário a realidade humano-social porque ele próprio é o produtor desta última realidade (KOSIK, 1995, p. 15).

Para dissolver um mundo reificado, circunscrito ao homem, e alcançar a sua realidade, só se dá numa práxis revolucionária, na medida em que os homens tomem consciência de que podem tanto produzir a realidade humano-social, quanto podem mudá-la ou transformá-la. Para tal não pode haver separação entre sujeito e objeto, gênese e estrutura, produção e produto: o todo é complexo e inter-relacionado.

É na própria práxis que o homem vai conhecendo a coisa em si, num movimento ativo e não contemplativo, isso ocorre nos diversos modos de apropriação do mundo que os homens utilizam e criam para entendê-lo. $\mathrm{O}$ foco central de um estudo desta natureza está no terreno da práxis humana: a docência e suas relações com os outros docentes, discentes, estrutura social, econômica e histórica a que pertencem, "posto que a realidade social dos homens se cria como união dialética de sujeito e objeto" (KOSIK, 1995, p. 20). Nesse movimento há contradições que precisam ser compreendidas dentro de um todo e não dele se excluindo. A isso Kosik (1995) chama de totalidade concreta.

É a compreensão da realidade humano-social como unidade de produção e produto, de sujeito e objeto, de gênese e estrutura. $\mathrm{O}$ mundo real é um mundo em que as coisas, as relações e os significados são considerados como produtos do homem social, e o próprio homem se revela como sujeito real do mundo social (KOSIK, 1995, p. 18).

$\mathrm{Na}$ perspectiva da totalidade é que a formação continuada dos professores deve ser vista como parte de um todo histórico pertencente a uma totalidade complexa. Ao mesmo tempo em que é particular, devido a 
sua especificidade, só tem sentido se sua essência for buscada na totalidade da qual faz parte. "A dialética materialista, como método de explicitação científica da realidade humano-social, acontece ou se realiza partindo da atividade prática objetiva do homem histórico" (KOSIK, 1995, p. 32).

A partir desses pressupostos histórico-antropológicos e epistemológicos, aborda-se também o processo de alienação do trabalhador. Este é um aspecto da realidade educacional importante que precisa ser mais discutido e considerado, tanto na docência quanto no processo formativo continuado. Tal processo é provocado pela cisão entre significado social da formação continuada e sentido pessoal de tal ação para os docentes.

Sabe-se que o trabalho docente no mundo contemporâneo com seus inúmeros desafios tais como a imprevisibilidade, a globalização, a instabilidade, os desgastes psicológicos, emocionais e físicos, provocam de certo modo, mudanças na atividade assumidas como algo externo, só como um meio de sobrevivência, no qual, o trabalho executado pelo docente passa a não fazer parte de sua natureza humana.

É nesse sentido que se entende o processo de alienação: quando o docente acaba alienando a si mesmo, na consecução de sua atividade docente; quando participa de cursos de formação continuada docente, unicamente para atender necessidades e exigências mercadológicas, cedendo à competitividade exacerbada, à incorporação de atualização das informações, com intuito de agregar cada vez mais valor à sua carreira, como um produto que só vai ser valorizado se for usufruído pelo mercado. Tornando-se assim um meio para satisfazer outras necessidades. Segundo Marx (apud FROOM, 1979, p. 23) essa alienação assim se constitui:

O que constitui a alienação do trabalho? Primeiramente, ser o trabalho externo ao trabalhador, não fazer parte de sua natureza, e, por conseguinte, ele não se realizar em seu trabalho, mas negar a si mesmo, ter um sentimento de sofrimento em vez de bem-estar, não desenvolver livremente suas energias mentais e físicas mas ficar fisicamente exausto e mentalmente deprimido. $\mathrm{O}$ trabalhador só se sente à vontade em seu tempo de folga, enquanto no trabalho se sente contrafeito. Seu trabalho não é voluntário, porém imposto, é trabalho forçado. Ele não é satisfação de uma necessidade, mas apenas 
um meio para satisfazer outras necessidades. Seu caráter alienado é claramente atestado pelo fato de, logo que não haja compulsão física ou outra qualquer, ser evitado como uma praga (MARX, [S.1.: s.n.] apud FROOM, 1979, p. 93).

Pensar o processo de formação continuada, na maioria das vezes, sentido e vivenciado pelos professores como algo externo à sua atividade docente, como algo sofrível tanto para a sua ação na sala de aula, quanto para sua participação em programas e/ou projetos de formação, implica reconhecer a possibilidade de ocorrer alienação nos termos aqui apresentados. É perceptível tal situação nas relações existentes nos contextos de formação continuada docente, nas escolas, nas falas dos professores, nos comportamentos e na cultura escolar.

O trabalho executado pelo professor nessas condições é demonstrado como não sendo trabalho dele mesmo, mas trabalho de outro, para outro. Formação continuada em programas e/ou projetos a partir dos quais o professor não o assume, por condições inerentes à sua natureza de ser social, como desejo de autorealização, de necessidade formativa, com significação social e sentido pessoal, mas tão somente por exigência do mercado competitivo, por demanda legal ou governamental, passa a ser alienado e alienante, o que é ainda pior.

O desafio para a comunidade acadêmica e escolar, no campo da profissionalidade docente é, sem dúvida, a superação de um trabalho docente alienado, deixar de ser refém do objeto que produz e do processo de produção. Enfim, exercer a autonomia, não se sujeitar à condição de trabalho somente para a sobrevivência, mas que este seja uma prática social emancipatória, no sentido de interpelar o quê, para quê, para quem se educa e como se exerce a docência.

Não fazer da profissão docente e do processo de formação continuada somente o labor (processo biológico do corpo humano-sobrevivência) e trabalho (mundo artificial produzido pelo homem) como Hanna Arendt (1987) discute, mas esforçar-se por constituir uma vida de ação, na relação dos homens entre si, em suas igualdades (todos são humanos) e em suas singularidades (pensamentos e atitudes diferentes), a fim de exercerem no coletivo a condição humana politizada, consciente e não alienada. 
Articulando essas concepções ao campo da ação educacional, no sentido trabalhado por Arendt (1987), emergem algumas questões: as ações na escola passam pela lógica do labor, do trabalho ou da ação? O que se tem feito para que os alunos e também os professores, em situação de formação continuada, sejam sujeitos do processo e não apenas receptores e/ou produtos? Há como evitar processos alienantes no cotidiano da escola e nas ações de formação continuada? Que caminhos podem ser construídos para a superação de relações alienantes e a constituição de atividades que realmente desencadeiem formação?

No contexto de tais indagações, os diálogos com Heller (2004, p. 18) são profícuos, pois ao tratar da cotidianidade, a autora discute a complexidade pertinente a qualquer configuração social, demonstrando que a vida cotidiana é heterogênea e hierárquica.

A heterogeneidade é imprescindível para conseguir essa "explicitação normal" da cotidianidade; e esse funcionamento rotineiro da hierarquia espontânea é igualmente necessário para que as esferas heterogêneas se mantenham em movimento simultâneo (HELLER, 2004, p. 18).

Segundo a autora, várias são as partes orgânicas da vida cotidiana: o modo como os homens se organizam no trabalho, como se relacionam nas diversas atividades de lazer, no social, na vida privada, entre outras. A importância dada à função das atividades do cotidiano pode se alterar de acordo com as diferentes estruturas econômicas e sociais apresentadas ao homem. Isso precisa ser levado em conta quando se discute o próprio trabalho docente e o seu processo formativo.

Partindo, pois, dessa perspectiva, pensar o cotidiano escolar, implica pensar no homem, no professor, na sua subjetividade, nas suas formas de conceber, sentir e agir no mundo, o que implica pensar, também, em como se dá a formação desse homem/mulher, desse professor, tendo em vista que a formação não acontece isoladamente, mas num determinado contexto sócio-histórico e mediado por outros indivíduos. "A vida cotidiana não está "fora" da história, mas no "centro" do acontecer histórico: é a verdadeira “essência” da substância social” (HELLER, 2004, p. 20). 
Refletir, discutir e compreender como a cultura escolar, dentro da qual se constitui o professor e da qual é também constituinte, representa um sistema subjetivo, gerador de subjetividade, é essencial. A formação docente não ocorre somente ou totalmente $a$ priori, na formação inicial, nem tampouco a posteriori, em programas de formação continuada, mas ao longo do processo de desenvolvimento deste ser humano mediatizado pelo trabalho, vinculado diretamente à sua vida concreta, às suas necessidades e motivos.

Nesse sentido, se a vida cotidiana é a vida do indivíduo e ela não está desvinculada do social, da própria história da humanidade, pode-se dizer, como Gonzalez Rey (2005), que a formação de sua subjetividade e a constituição de sua história como sujeito operam, não como relação de um no outro, mas como recursividade ${ }^{4}$ na cotidianidade e não fora dela.

O cotidiano escolar é composto por conjuntos de atividades para a reprodução da existência do indivíduo e da sociedade, uma vez que o homem é simultaneamente um ser particular e genérico. "A vida cotidiana é a vida do indivíduo. O indivíduo é sempre, simultaneamente, ser particular e ser genérico" (HELLER, 2004, p. 20).

Essas objetivações genéricas e particulares representam o próprio desenvolvimento histórico da humanidade, as marcas de sua evolução e se encontram em processos de constante transformação. Dentro dessa perspectiva há uma forte relação nos processos objetividade-subjetividade, não havendo entre eles dicotomias, justamente por haver uma compreensão dialética entre o sujeito individual e a vida social.

[...] a particularidade expressa não apenas seu ser "isolado", mas também seu ser "individual" [...] Também o genérico está "contido" em todo homem e, mais precisamente, em toda atividade que tenha caráter genérico, embora seus motivos sejam particulares. Assim, por exemplo, o trabalho tem freqüentemente motivações particulares, mas a atividade do trabalho-quando se trata de trabalho efetivo (isto é, socialmente necessário)-é sempre atividade do gênero humano (HELLER, 2004, p. 20-21).

\footnotetext{
${ }^{4} \mathrm{O}$ conceito de recursividade em Gonzalez Rey significa a configuração de novas qualidades a partir das contradições e confrontações do sistema em seu desenvolvimento, a coexistência do diferenciado e do singular, como momento constituinte do sistema, entre outros aspectos caracterizadores da subjetividade (GONZALEZ REY, 2005, p. 37).
} 
Os docentes exercem sua atividade mediante seus próprios desejos, necessidades, com seus afetos e paixões, contudo essa particularidade está socialmente mediatizada, como afirma Heller (2004), pois, "é também produto e expressão de suas relações sociais" (HELLER, 2004, p. 21). Portanto, a sua atividade docente e, também, seu processo de formação continuada, seu desenvolvimento, só podem ser compreendidos e explicados a partir de sua integração aos contextos de trabalho docente, que é sempre coletivo.

Por isso, de acordo com Marx ([S.1.: s.n.] apud FROOM, 1979) e Heller (2004), há como afirmar que as ações dos homens não são neutras, pois nas diversas relações que estabelecem no mundo do trabalho docente, os professores podem ao mesmo tempo formar a sua consciência de nós, bem como sua própria consciência do eu. É claro que esse processo não se dá espontaneamente, necessita haver uma intencionalidade nas ações coletivas, que, por sua vez, acontecem sempre mediatizadas. Daí a relação entre formação da subjetividade e cotidianidade.

Compreender esse movimento na tecitura das relações educativas e no processo formativo é buscar romper com a naturalidade com que é aceita a situação social e psicológica de alienação que pode marcar a vida do indivíduo contemporâneo. "Trata-se de algo que pode ser expresso com as palavras de Goethe: "...todo homem pode ser completo, inclusive na cotidianidade" (GOETHE [S.1.: s.n.] apud HELLER 2004, p. 40).

É buscar compreender o significado da escola como espaço também formativo, no que se refere ao todo, ao social, ao coletivo, bem como o sentido pessoal de tal formação para o docente, pois como afirma Leontiev (1978), o sentido pessoal é engendrado, produzido na vida do sujeito, em sua atividade, é desta, que surgem as necessidades formativas, que potencializam o desenvolvimento pessoal e profissional docente.

\section{A Teoria da Atividade e sua relação com a natureza sociohistórica do psiquismo humano: contribuições para formação continuada}

A Teoria da Atividade de Aleksei Nikolaesvich Leontiev (19031979), psicólogo pertencente à escola soviética é, segundo Duarte (2003), considerada um desdobramento do esforço para construção de uma psicologia sócio-histórico-cultural, fundamentada na filosofia marxista. 
Uma das principais preocupações de Leontiev (1978) encontra-se no estudo das relações entre o desenvolvimento do psiquismo humano e a cultura, ou seja, entre a evolução das funções psíquicas e a assimilação individual da experiência histórica.

Preocupa-se com os problemas da vida humana em que o psiquismo intervém. Leontiev (1978) critica as concepções mecanicistas do comportamento humano, buscando a construção de um referencial materialista, histórico e dialético para a psicologia. Defendendo a natureza sócio-histórica do psiquismo humano e, a partir daí, a teoria marxista do desenvolvimento social torna-se algo indispensável.

Os clássicos trabalhos de Leontiev $O$ desenvolvimento do psiquismo (1978) e Actividad, conciencia e personalidad (1983), bem como Linguagem, desenvolvimento e aprendizagem de Vigotski, Luria e Leontiev (1981), trazem para discussão a formação do psiquismo humano e a íntima relação entre a estrutura objetiva da atividade humana e a estrutura subjetiva da consciência. Leontiev (1978) considera que essa formação é complexa por situar-se na inter-relação indivíduo-sociedade. A complexidade dessa relação está permeada pela atividade de trabalho na sociedade capitalista. O trabalho executado pelo homem, tanto pode contribuir no sentido da formação humanizadora da consciência, quanto pode contribuir para a formação alienante da mesma.

Na relevante produção desta famosa tróica da psicologia, Vigotski, Luria e Leontiev, cuja base fundamenta-se na psicologia do homem social, as categorias consciência e atividade estão imbricadas na constituição do indivíduo, uma vez que:

[...] mesmo em uma situação íntima, no movimento pensante individual, no sentimento, etc., o psiquismo de um homem considerado isoladamente continua sendo social e está determinado socialmente (GOLDER, 2004, p. 20).

As categorias consciência e atividade são compreendidas nas relações de trabalho dos homens, no caso aqui específico, no trabalho dos professores, nas formas como estes se produzem por meio de suas atividades, "estudar como a estrutura da consciência do homem se transforma com a estrutura da sua atividade" (LEONTIEV, 1978, p. 92). 
Pode-se dizer que para compreender melhor as ações de formação continuada vivenciadas pelos professores, segundo a perspectiva teóricometodológica da atividade, é importante entender alguns de seus conceitos chave. Os elementos constitutivos da Atividade são: estrutura da atividade, atividade dominante, significado social e sentido pessoal. A estrutura da atividade é constituída, segundo Leontiev (1978), por: necessidade, motivo, operação, ação, condições e objeto.

Uma necessidade é um requisito para qualquer atividade. Todavia ela não consegue se realizar, senão, no objeto da ação, quando se objetiva nele. Leontiev (1978b) assim se referiu à necessidade:

A primeira condição de toda a actividade é uma necessidade. Todavia, em si, a necessidade não pode determinar a orientação concreta de uma actividade, pois é apenas no objecto da actividade que ela encontra sua determinação: deve, por assim dizer, encontrar-se nele. Uma vez que a necessidade encontra a sua determinação no objecto (se "objectiva" nele), o dito objecto torna-se motivo da actividade, aquilo que o estimula (LEONTIEV, 1978, p. 107-108).

Por conseguinte, quando o sujeito consegue articular uma necessidade a um objeto ele o faz por meio do motivo, que o impele a buscar a satisfação daquela necessidade. Há deste modo, uma estreita relação entre necessidade, motivo, objeto e condições, presentes na estrutura da atividade.

O motivo diz respeito àquilo que impulsiona o comportamento do sujeito, o que move sua ação, e este, por sua vez, se relaciona diretamente a uma necessidade que se quer satisfazer.

Entretanto, para satisfazer essas necessidades, o sujeito depende das condições que se têm, ou do modo pelo qual são executadas. Essas condições são compreendidas como o conteúdo indispensável de toda ação, mas não se identifica com a ação. Uma só e mesma ação podem realizar-se por diferentes operações. Enquanto a ação é determinada pelo seu fim, as operações dependem das condições em que é dado este fim. Isto é, como essas necessidades são satisfeitas.

Quando o motivo é impulsionado por uma necessidade, e esta consegue ser objetivada no objeto, diz-se que tal relação é capaz de conferir 
significado à ação e ter um sentido para quem a realiza. Por conseguinte, a formação continuada por si só não confere significado ao motivo, mas sim, o motivo que se exprime nos fins, ou seja, é o sentido que se exprime nas significações e não a significação no sentido.

Sentido e significado, embora sejam conceitualmente diferentes, possuem uma relação na estrutura da atividade. Por isso, Leontiev (1978) afirma que nem toda ação é uma atividade para o sujeito que a realiza. Só se constitui uma atividade, quando o motivo que leva o indivíduo a agir diz respeito ao conteúdo da ação. "Usando os termos de Leontiev, ao conteúdo da ação, isto é, àquilo que constitui seu objeto, vincula-se o significado da ação, ou seja, o significado da ação é aquilo que o sujeito faz" (DUARTE, 2005, p. 36, grifo do autor). O significado pode ser compreendido com a pergunta: fazer isto ou aquilo para quê? $O$ objeto da ação pode ser compreendido como sendo a finalidade da ação.

Contudo, o significado da ação, não está isolado no indivíduo. A consciência humana considera que existe uma relação entre o significado e o sentido da ação. Leontiev (1983) preocupa-se com essa relação e para ele, "[...] o sentido da ação é dado por aquilo que liga, na consciência do sujeito, o objeto de sua ação (seu conteúdo) ao motivo da mesma" (DUARTE, 2005. p. 36). Há de existir uma relação entre o significado social e o sentido pessoal, ou no caso contrário, percebe-se a questão da alienação tão contundente na sociedade contemporânea.

Nesse sentido, Leontiev (1983) analisa que na natureza da atividade humana, marcado por contradições na história da sociedade de classes e na divisão social do trabalho -, pode acontecer uma cisão entre o significado da ação do trabalhador e o sentido pessoal que essa ação tem para si. Assim, há claro uma separação do conteúdo da ação com o motivo pelo qual o indivíduo age. Essa é, pois, uma relação de alienação.

O termo sentido pessoal, empregado na teoria da Atividade, não está relacionado ao idealismo subjetivista, não se refere ao fato do sujeito encarar as coisas de um modo diferente, mas sim, encarar como as próprias condições objetivas têm afetado o exercício do seu trabalho docente, muitas vezes, dissociado do seu conteúdo. A ruptura entre sentido e significado 
tem como uma de suas conseqüências o cerceamento do processo de desenvolvimento da personalidade humana. Isso ocorre porque o indivíduo, por vender sua força de trabalho e, em decorrência disso, ter o sentido de sua atividade como algo dissociado do conteúdo da mesma, acaba distanciando o núcleo de sua personalidade da atividade de trabalho (DUARTE, 2005, p. 37).

Sabe-se da importância de se considerar o caráter social das atividades humanas, as relações de dominação e os processos de alienação historicamente produzidos. Assim, alguns questionamentos suscitam nesse sentido: a formação continuada é vista, ou melhor, exercida pelo professor como algo externo ao seu trabalho docente, como uma exigência mercadológica, dissociada do conteúdo de sua atividade? Há um esforço empreendido, nesta formação continuada, tendo em vista receber algo em troca como aumento no salário, ascensão na carreira, ou ainda, para melhorar a sua avaliação de desempenho, sobrepondo-se ao interesse de desenvolvimento humano, em seu aspecto tanto pessoal quanto profissional? Existe uma profunda ligação das ações de formação continuada com o conteúdo do seu trabalho, com sua atividade docente, com suas necessidades de crescimento, a fim de melhorar o que faz em sala de aula com seus alunos, envolvê-los no processo de construção e desenvolvimento do conhecimento, enfim, contribuir para o processo de formação dos discentes, bem como o seu também?

A docência é o meio objetal no qual o professor está inserido, mediatizado pelas relações sociais, e é da docência, de sua atividade que advém necessidades formativas, que por sua vez, o impele a buscar meios para essa satisfação, é o motivo real que impulsiona a atividade. Nesse sentido, afirma-se que consciência e atividade social são indissociáveis. Estudar os sujeitos, "o que precisam", "o que necessitam" nesse processo de formação continuada, requer estudar as relações que estes estabelecem por meio de suas atividades, em suas condições concretas, seus motivos e sentimentos.

Entende-se condição da atividade, a relação entre significação social e sentido pessoal da "formação continuada", ou seja, se os instrumentos, as formas e como a atividade se realiza correspondem ao que se busca 
satisfazer, e simultaneamente, ao significado da ação, uma vez que é o sentido pessoal o motivo da atividade.

Segundo o aporte teórico leontieviano, a relação social estabelecida entre os homens pela linguagem e pelo trabalho que executam permite a apropriação das significações sociais. Inclusive o significado social da formação continuada docente só pode ser apreendido enquanto tal, à medida que tiver um sentido pessoal para si mesmo, se houver um vínculo significativo com o trabalho, se houver uma necessidade e um motivo que o impulsiona a essa apropriação.

O significado social está relacionado ao mundo dos fenômenos objetivamente históricos, isto é, ao que já se encontra no mundo socialmente produzido pela humanidade e apropriar-se ou não dessas significações sociais depende do sentido pessoal que isto tem para o sujeito, se tem relação com sua atividade, com seu trabalho.

Acredita-se na necessidade de olhar "as pessoas em atividades específicas, considerando o movimento de significações (re)produzidas, transformadas e apropriadas em contextos sociais específicos" (ZANELLA, 2004, p. 133), o que denota a relevância do contexto escolar no qual o professor exerce a docência, mediatizada pelos demais colegas de profissão, alunos, gestores, funcionários, comunidade local e toda a relação de poder que permeia este ambiente de trabalho.

A formação continuada do professor, embora tenha o significado social de crescimento, de conhecimento e autorealização, muitas vezes não se relaciona com o sentido pessoal de quem decide apenas participar de um programa de formação continuada para simplesmente atingir níveis diferenciados em seu plano de carreira e na avaliação de desempenho.

No sentido exposto acima, ocorre uma cisão entre significado social e sentido pessoal da formação continuada, "[...] o sentido pessoal da ação não corresponde mais ao seu significado" (BASSO, 1998, p. 27), e isto pode contribuir para a perpetuação de práticas inibidoras do crescimento deste profissional do ensino, o professor.

Considerando este referencial, a formação continuada passa a se constituir em um processo alienado quando o sentido pessoal não corresponder ao significado social. O significado social deste processo formativo deveria ser o de promover a sua participação na produção 
das objetivações, na perspectiva da genericidade, da busca incessante do aprimoramento cultural próprio e dos discentes. Todavia, a formação continuada, muitas vezes, tem sido compreendida pelos professores, como tão somente um meio de melhorar o salário, de garantir emprego, a sobrevivência e atender às pressões mercadológicas.

Isto pode ocorrer por vários motivos, talvez seja porque tais ações não consideram ou pouco se relacionam com o mundo do trabalho e com as suas condições objetivas, ou porque a frequência em tais ações tem sido mais valorizada do que o próprio desempenho e crescimento pessoal docente. Dependendo da forma como se organizam ou realizam essas ações, os motivos podem se deslocar do conteúdo da ação, não se objetivar nela.

A partir desta análise, o presente estudo, de cunho teóricometodológico, procura incidir de forma propositiva na busca de ações de formação continuada que sejam críticas e emancipadoras, que permitam aos sujeitos envolvidos em processos formativos questionar suas condições objetivas de docência, questionar seus tempos e espaços de formação dentro e fora das escolas.

De acordo com Duarte (2003, p. 293), “[...] o caráter social das atividades humanas não se reduz ao uso de instrumentos e linguagens socialmente produzidas, envolvendo também relações de dominação e processos de alienação historicamente produzidos". Construir e estabelecer outras relações requer certos enfrentamentos, e estes só ocorrem mediante a conscientização por parte dos professores, das suas condições objetivas de docência, da sua realidade social e cultural.

Entende-se que a formação continuada é um espaço para o sujeito compreender a sua própria historicidade e nela poder intervir e não somente reproduzir o que já está determinado. Então, particularmente neste estudo, cabe indagar: até que ponto as ações de formação continuada têm ou não contribuído para que se superem os fatores de alienação que também podem ocorrer no processo de formação continuada?

No campo da formação continuada de professores, a superação do distanciamento entre significado social e sentido pessoal, em outros termos, a superação das resistências em participar das ações de formação, implica na construção de condições objetivas a partir das quais seja possível a construção de trabalhos que não somente incluam os professores em seus 
processos de formação, mas que também possibilitem a constituição de coletivos que assumam suas necessidades e as transformem em atividades formativas, potencializadoras do desenvolvimento profissional docente.

A preocupação com estes fatores precisa extrapolar o campo dos estudos dos pesquisadores das academias para o campo da prática dessa formação continuada, nos espaços escolares, com os gestores, com os professores e com os formadores de formadores. É salutar repensar nas práticas de formação que são desenvolvidas nos ambientes escolares (formação em serviço) ou em ações específicas, bem como, quais são as necessidades formativas dos professores. Aqui cabem algumas considerações relevantes sobre o formador de formadores.

$\mathrm{O}$ formador de formadores se configura como alguém que conhece o grupo ou que dele faz parte e, por isso, exerce a função de mediador. Para tal é necessário que esse formador tenha conhecimentos teórico-metodológicos da formação docente, que compreenda a sua ação neste coletivo, como um processo também de formação para si mesmo e para os outros.

O profissional que, parte de um coletivo ou se constituindo parte dele, media a construção de conhecimentos com outros profissionais para, em conjunto, compreenderem e apreenderem conceitos e práticas próprias do exercício profissional docente (ALVARADO PRADA, 2003, p. 76).

Portanto, não se trata de ser um transmissor de informações, técnicas e procedimentos para aqueles que, supostamente, não os tenha. Há uma postura epistemológica e filosófica que sustenta esta outra forma de processar o conhecimento, de se fazer educação, enfim, de considerar a formação continuada dos professores como um processo continuado, construído no coletivo de saberes e fazeres, na relação dialógica e contextualizada.

Uma das propostas que trabalham nesta vertente é a formação em serviço, com fundamentos teórico-metodológicos da pesquisa coletiva ${ }^{5}$.

${ }^{5}$ Cf. ALVARADO PRADA, L. E. Pesquisa Coletiva na Formação de Professores. Revista de Educação Pública, Cuiabá, v. 15, n. 28, Maio/ago. 2006. A pesquisa coletiva enunciada e desenvolvida por este autor pretende a construção de conhecimentos, junto a coletivos de participantes e mediante processos de pesquisa-formação. Assume 
Essa proposta não exclui a necessidade de encontros de formação fora do contexto escolar, desde que, estes momentos sejam, verdadeiramente, espaços para socialização de conhecimentos e experiências interinstitucionais, de relações interpessoais, de redes de colaboração entre os professores e os diversos contextos em que atuam.

A formação de professores pela pesquisa coletiva apóia-se na ideia de que, ao considerar o campo de trabalho docente e suas especificidades, os professores podem fortalecer as relações cotidianas, por intermédio de estudos coletivos, diálogos inerentes às necessidades formativas dos professores, enquanto pessoas e profissionais da educação.

Como salienta Alvarado Prada (2003) "[...] a formação docente depende de metodologias que quebrem as rotinas do professor entraves na educação - e as transformem em dinâmicas de construção de conhecimento" (ALVARADO PRADA, 2004, p. 77). Tal metodologia nos processos formativos coaduna com a perspectiva da Teoria da Atividade, uma vez que tem no mundo do trabalho docente e nas necessidades formativas dos que a executam, o seu foco central.

Outras propostas de pesquisa desenvolvidas no Brasil e em alguns países, também com foco na formação continuada em serviço, (GARRIDO, 1998; SERRÃO, 2004; ANDRÉ, 1994; LONGAREZI, 1996, 1997, 2006; DUARTE, 2003, 2005; MOURA, 1996, 2000, 2002; ZANELLA, 2004; CANÁRIO 1998; KINCHELOE, 1993; NÓVOA, 1991, 1992 etc.) têm demonstrado novas possibilidades metodológicas, novas dinâmicas de participação dos próprios docentes em seu processo formativo. Muitas dessas propostas têm partido do princípio de que é no diálogo, na inter-relação entre os conhecimentos práticos do professor e os conhecimentos teóricos, que o professor terá melhores condições de rever sua prática de forma crítica e construir uma práxis crítico-reflexiva.

Assim, com o olhar da perspectiva histórico-cultural da atividade, cabe analisar a organização e o desenvolvimento das ações de formação continuada e, também, como estas contribuem com o desenvolvimento pessoal e profissional docente, bem como com a melhoria da prática pedagógica.

um caráter formativo e transformador da realidade social, à medida que o coletivo compreende a dinâmica constituinte da totalidade a que pertencem. Tem uma relação tridimensional nesse tipo de pesquisa: a comunicação, identidade e transformação. 
Para esta análise deve-se partir da própria prática formativa vivenciada, do contexto micro e macro ao qual pertencem, por entendê-los como aspectos essenciais no processo de desenvolvimento profissional do docente.

\section{A formação docente como Atividade}

Cada indivíduo aprende a ser um homem. O que a natureza lhe dá quando nasce não the basta para viver em sociedade. É-lhe ainda preciso adquirir o que foi alcançado no decurso do esenvolvimento histórico da sociedade humana (LEONTIEV, 1978, p. 67).

Neste momento cabe evidenciar as contribuições de cunho teórico leontieviano e os questionamentos suscitados pela perspectiva históricocultural, na tentativa de compreender o desenvolvimento do psiquismo humano, a partir das leis do desenvolvimento histórico-sociais e a formação continuada docente nesse contexto inserida. Entende-se que este desenvolvimento se processa nas interações do indivíduo com o seu meio físico e social, à medida que também incorpora a cultura acumulada pelas gerações por intermédio das relações de trabalho produzidas na sociedade.

Assim, o desenvolvimento profissional dos professores ocorre mediante processos formativos que consideram as relações sociais estabelecidas no exercício da docência. A aquisição da cultura e o desenvolvimento humano não são adquiridos passivamente por pressão do meio externo, tampouco pela herança genética, mas sim construídos mediante as relações sociais concretamente situadas. $\mathrm{O}$ trabalho docente não é aprendido exclusivamente em cursos de formação, ofertados aos professores como forma de melhor "capacitá-los", mas é constituído no exercício da docência.

Por essa razão, as relações sociais existentes no processo de desenvolvimento dos professores, o meio físico, social, histórico e cultural dos sujeitos necessitam ser apreendidos pela ótica dos que vivenciam esse processo formativo: Qual o significado social e o sentido pessoal das ações formativas para os professores? Como as ações de formação continuada podem se configurar em atividade dominante e impulsionar o desenvolvimento da profissionalidade docente? 
De acordo com a Teoria da Atividade, o desenvolvimento da profissionalidade docente ocorre mediante a atividade de trabalho, a docência, e do seu conteúdo, o qual muda com as condições sóciohistóricas. As necessidades formativas se reconfiguram de acordo com essas condições. É por isso que é possível dizer que sua atividade se reorganiza.

É importante situar as ações de formação continuada dentro dessas necessidades historicamente produzidas na sociedade contemporânea. A própria atividade docente se reorganiza considerando as transformações do mundo e do modo com as pessoas se relacionam com ele. E como os professores se veemnesse processo de desenvolvimento da profissionalidade docente? Como percebem as ações de formação continuada e suas necessidades formativas? Há relações entre as duas, e delas, com o seu trabalho? A formação continuada é uma atividade dominante para a constituição de sua profissionalidade docente?

Conforme mencionado anteriormente, para Leontiev (1978) nem todo o processo é uma atividade. Só se configura atividade quando o objeto, a finalidade do ato, coincidir com o elemento objetivo que incita alguém a agir, o motivo:

Os processos que são psicologicamente determinados pelo fato de aquilo para que tendem no seu conjunto (o seu objeto) coincidir sempre com o elemento objetivo que incita o paciente a uma dada atividade, isto é, com o motivo (LEONTIEV, 1978, p. 315).

Sempre que o motivo que impele o indivíduo a agir coincidir com o que ele faz, ou melhor, com o conteúdo da ação, com a função do objeto, é considerada uma atividade. Quando o motivo que impele o indivíduo a agir não coincidir com o objetivo visado, trata-se de uma ação.

Há na Teoria da Atividade, "[...] uma relação particular entre a atividade e a ação. O motivo da atividade, deslocando-se pode tornar-se objeto (o fim) do ato.

Resulta daqui que a ação se transforma em atividade. Este elemento é de suma importância" (LEONTIEV, 1978, p. 317). Como transformar as "ações" em "atividades dominantes" e, por consequência, 
proporcionar as passagens de um estágio de desenvolvimento a outro da profissionalidade docente?

As ações de formação continuada podem se transformar em atividade dominante na vida docente, à medida que o motivo dos professores se relacionar com o conteúdo da ação, e isso têm ligação direta com as condições concretas da sua vida docente. Se as relações do professor com a realidade se modificam na tentativa de suprir as suas necessidades e interesses, significa dizer que as ações de formação continuada também devem ser reorganizadas em sua vida docente. Essas ações passam a ter sentido para o professor, pois significam algo extremamente valioso para sua atuação pedagógica e pessoal, enfim, na prática social concreta.

Por essa razão, Leontiev (19878) afirma que a atividade dominante tem papel importante no desenvolvimento do psiquismo humano e na formação de sua consciência. A atividade dominante não se refere àquela que o indivíduo dedica maior parte do tempo, não se trata de quantidade, e sim às mudanças psicológicas de uma dada etapa do seu desenvolvimento.

O conteúdo de uma ação de formação continuada precisa ter ligação com o trabalho que o docente executa para que realmente esta venha a ter um significado social.

[...] o seu conteúdo não é de modo algum independente das condições históricas concretas em que se desenrola o desenvolvimento; depende mesmo, antes de mais nada de todas estas condições. A influência das condições históricas concretas exerce-se tanto o conteúdo concreto de tal ou tal estágio dado do desenvolvimento, como sobre o curso do processo de desenvolvimento psíquico no seu conjunto (LEONTIEV, 1978, p. 312).

Portanto, desconsiderar tais contextos sociais e historicamente existentes na formação docente, é desconsiderar o próprio processo de desenvolvimento profissional, que também se reconfigura à medida que crescem as necessidades da sociedade na qual exerce sua função docente. Assim, modificam-se os interesses e necessidades docentes, e para tais motivos, as ações de formação continuada precisam estar intimamente relacionadas. 
Se o seu trabalho exige-lhe determinadas atitudes ou conhecimentos, vai se esforçar em satisfazê-los para suprir seus interesses e suas necessidades. Contudo, se nesse movimento houver uma ruptura, uma cisão entre o que deseja e o conteúdo do objeto, há um distanciamento entre o significado social da ação e o sentido pessoal que o homem psicologicamente determinou para si. A ação deixa de ser importante para o seu desenvolvimento, não se caracterizando em atividade dominante.

A formação continuada será para o professor uma atividade dominante se ele encontrar nestas ações, uma relação direta com seu trabalho, uma aproximação direta do conteúdo da ação com suas necessidades. Nesse sentido, diversas ações, articuladas entre si e com o contexto escolar, podem se transformar em atividades formativas potencializadoras do desenvolvimento docente.

$\mathrm{O}$ aporte leontieviano oferece contribuições significativas para a construção de processos formativos com os docentes, em situações de trabalho, na escola ou fora dela, pois se tem o entendimento de que a formação da estrutura da consciência do homem se transforma com a estrutura da sua atividade.

Tendo em vista os pressupostos da teoria da atividade aqui salientados, pode-se afirmar que não basta oferecer formação continuada docente, mas construir coletivamente caminhos, alternativas, propostas de ação que estejam integradas às necessidades da atividade docente e à complexidade do desenvolvimento humano pessoal e profissional.

\section{Referências}

ALVARADO PRADA, L. E. Pesquisa coletiva na formação de Professores. Revista de Educação Pública, Cuiabá,. v. 15, n. 28, Maio/ago. 2006.

. Formação continuada de Professores em Serviço: Formação de Formadores. In: MONTEIRO, F.M. de A.F.; MÜLlER, M. L.R.(Org.). Profissionais da Educação-politicas formação e pesquisa. Cuiabá: EDFMT, 2003. v. 2. 
ANDRÉ, M. O papel da pesquisa na articulação entre saber e prática docente. In: ENCONTRO NACIONAL DE DIDÁTICA E PRÀTICA DE ENSINO, 7., 1994, Goiânia. Anais... Goiânia: UFGO/PUC, 1994. v.2. p. 291-296.

ARENDT, H. A condição humana. Rio de Janeiro: Forense Universitária, 1987.

BASSO, I. S. Significado e sentido do trabalho docente. Cadernos CEDES, Campinas, v. 19, n. 44, Apr. 1998. Disponível em: <http://www.scielo.br/ scielo.php? script=sci_arttext\&pid=S0101-32621998000100003\&lng=en $\&$ nrm=iso $>$. Acesso em: 22 jul. 2009.

CANÁRIO, R. A escola: o lugar onde os professores aprendem. Psicologia da Educação, São Paulo, n. 6, p. 9-27. jan./jul. 1998.

DUARTE, N. A teoria da atividade como uma abordagem para a pesquisa em educação. Perspectiva Revista do centro de ciências em Educação, Florianópolis, v. 21, n 02, jul./dez. 2003.

. O significado e o sentido. Coleção Memória da Pedagogia. Suplemento especial. Viver mente e cérebro. São Paulo: Duetto, 2005. v. 2. FROOM, E. O conceito marxista do homem. Rio de Janeiro: Zahar, 1979. GARRIDO, E. A pesquisa colaborativa como abordagem facilitadora para o desenvolvimento da vida e da profissão do professor e para a introdução de práticas inovadoras na escola. São Paulo: UNESP, 1998.

GOLDER, M. (Org.). Leontiev e a psicologia histórico-cultural: um homem em seu tempo. Grupo de estudos e Pesquisas Sobre a Atividade Pedagógica. São Paulo: Xamã,

2004.

GONZALEZ REY, F. Sujeito e subjetividade. São Paulo: Thompson Editores, 2003.

. O valor heurístico da subjetividade na investigação psicológica. In:__. (Org.). Subjetividade, complexidade e pesquisa psicológica. São Paulo: Pioneira. 2005.

HELLER, A. Estrutura da vida cotidiana. Rio de Janeiro: Paz e Terra, 2004. 
HELlER, A. Estrutura da vida cotidiana. Rio de Janeiro: Paz e Terra, 2004.

KINCHELOE, J. L. Modernismo e passividade cognitiva da educação técnica do professor. In: - A formação do professor como um compromisso político. Porto

Alegre: Artes Médicas, 1993.

KOSIK, K. Dialética do concreto. Rio de Janeiro: Paz e Terra, 1995.

KOZULIN, A. O conceito de atividade na psicologia soviética: Vygotsky, seus discípulos, seus críticos. In: DANIELS, H. (Org.). Uma introdução a Vygostsky. São

Paulo: Loyola, 2002.

LEONTIEV, A. N. O desenvolvimento do psiquismo. Lisboa: Horizonte Universitário. 1978.

. Activity, consciousness, and personality. 1978b. Disponível em: $<\mathrm{http} / /$ www.marxists.org >. Acesso em: 18 abr. 2009. . Actividad, conciencia e personalidad. Havana: Editorial Pueblo y Educación. 1983.

LONGAREZI, A. M. Uma experiência de formação contínua: avaliando processos e produtos. 1996. 130f. Dissertação (Mestrado em Educação) Centro de Educação e. Ciências Humanas, Universidade Federal de São Carlos, São Carlos, 1996.

. Prática educativa e formação de professores. Revista UNIARA, Araraquara, v. 1, n. 2, 1997.

. Práxis e formação de professores: aspectos relevantes para se pensar uma epistemologia da formação docente. Revista \& Educação \& Linguagem, São Paulo. Ano 9, n. 14, jul./dez. 2006.

MARX, K.; ENGELS, F. A ideologia alemã (Feuerbach). 6. ed. São Paulo: Hucitec, 1987.

IANNI, O. (Org.). Sociologia. São Paulo: Ática, 1980.

FROMM, E. Conceito marxista de homem. Rio de Janeiro: Zahar Editores, 1979. 
MOURA, M. O. de. A atividade de ensino como ação formadora. In: CASTRO, A. D. de; CARVAlHO, A. M. de (Org.). Ensinar a ensinar: didática para a escola fundamental e média. São Paulo: Pioneira Thompson Learning, 2002.

- O educador matemático na coletividade de formação: uma experiência com a escola pública. 2000. 131f. Tese (Livre Docência) Faculdade de Educação, Universidade de São Paulo, São Paulo, 2000.

. A atividade de ensino como unidade formador. Bolema, São Paulo, ano II, n.12, p. 29-43, 1996.

NÒVOA, A. A formação tem de passar por aqui: as histórias de vida no projeto Praslus. In: . FINGER, M.(Org.). O método (auto) biográfico e a formação. Lisboa: Ministério da Saúde. Departamento dos Recursos Humanos da Saúde/Centro de formação e Aperfeiçamento Profissional, 1988.

. O passado e o presente dos Professores. In: . (Org.). Profissão Professor. Porto: Porto Editora, 1991. . Os professores e sua formação. Lisboa: Dom Quixote, 1992.

SERRÃO, M. I. B. Estudantes de pedagogia e a atividade de aprendizagem do ensino em formação. 2004. 200f. Tese (Doutorado em Educação) Faculdade de Educação, Univrsidade de São Paulo, São Paulo, 2004.

VAZQUEZ, A. S. Filosofia da práxis. Rio de Janeiro: Paz e Terra, 1977. VIGOTSKI, L. S.; LURIA, A. R.; LEONTIEV, A. N. Linguagem, desenvolvimento e aprendizagem. São Paulo: Cone, 1981.

ZANELLA, A. V. Atividade, significação e constituição do sujeito: considerações à luz da Psicologia histórico-cultural. Psicologia em Estudo, Maringá, v.9, n. 1, 2004.

Data de registro: 15/12/2009 Data de aceite: 15/09/2010 